Research Article

\title{
Experimental Study on the Anisotropic Characteristics and Engineering Application of Tight Sandstone
}

\author{
Yuanlong Wei, ${ }^{1}$ Wei Liu ${ }^{D},{ }^{2}$ and Zhenkun Hou ${ }^{2,3}$ \\ ${ }^{1}$ Guizhou Oil and Gas Exploration and Development Engineering Research Institute, Guiyang 553000, Guizhou Province, China \\ ${ }^{2}$ State Key Laboratory of Coal Mine Disaster Dynamics and Control, Chongqing University, Chongqing 400044, China \\ ${ }^{3}$ School of Materials Science and Engineering, South China University of Technology, Guangzhou 510640, China
}

Correspondence should be addressed to Wei Liu; whrsmliuwei@126.com

Received 5 August 2020; Revised 27 October 2020; Accepted 19 January 2021; Published 8 February 2021

Academic Editor: Sakar Mohan

Copyright (c) 2021 Yuanlong Wei et al. This is an open access article distributed under the Creative Commons Attribution License, which permits unrestricted use, distribution, and reproduction in any medium, provided the original work is properly cited.

The anisotropy of tight sandstone (a type of unconventional gas reservoirs) is a significant factor influencing the characteristics of cracks network under hydrofracturing; thus, it also has a large influence on the final production capacity of the gas reservoirs. To improve the understanding of anisotropy degree and mechanical properties of the tight sandstone of Xujiahe Formation and thus to provide reliable reference for the establishment of hydrofracture model and parameter designing in fracture field, a series of experiments including ultrasonic wave velocity and uniaxial and triaxial compression tests of the tight sandstone samples obtained from Xujiahe Formation with different inclination angles (the angle between sample drilling direction and bedding plane) have been conducted. With the increase of inclination angle, the velocity of the longitudinal wave and elastic modulus both show the tendency of decreasing, whereas the compressive strength shows a " $U$ " shape varying pattern, which is high on sides and low in the middle region. The values of uniaxial compression strength (UCS) are the lowest of sandstone with the inclination angles of $30^{\circ}$ and $45^{\circ}$. The fracture patterns are dominant by splitting fracture under uniaxial compression tests. However, shear fracture and dilatancy morphology is the main pattern under triaxial compression test. But the local morphology of the failure surfaces behaves different if the inclination angle is changed. Combining the mechanic theory of transversely isotropic material, the anisotropy parameters of the tight sandstone are analyzed, as well as the influence on the hydrofracturing technology for tight sandstone in the field.

\section{Introduction}

In China, under the situation of increasing natural gas supply, tight sandstone gas has become one focus of developing nonconventional/unconventional natural gas due to its wide distribution and rich reserves [1-5]. However, as a type of reservoirs with low porosity and low permeability, technological measures of increasing produciton must be taken to achieve an ideal capacity for the tight sandstone gas well [6-8]. Tight sandstone is a typical sedimentary rock mass. Usually, bedding planes are widely distributed in tight sandstone formations [9]. So, the influences of anisotropy on the physical and mechanical properties of tight sandstone are significant. In general, when the reservoir stratum contains bedding structure under hydrofracturing, cracks are prone to initiate along the bedding surface and then propagate in the matrix, acting as important impacts on the fracturing fracture network of the stratum as well as the ultimate production capacity [10]. From the perspective of mechanical properties, such property is named as anisotropy. Therefore, the anisotropic characteristics of the tight sandstone are a significant foundation and a prerequisite for the development of hydraulic fracturing.

Many theoretical and experimental studies have been carried out on the anisotropic characteristics of rock. Heng et al. [11] studied the anisotropic characteristics of shale by direct-shear test and revealed that the general anisotropy strength characteristic curve is $U$-shaped with the increase of the bending angle. Zhang et al. [12-14] studied the 
anisotropic strength characteristics of bedded composite rock and established a Figureure to show the change of strength with the bedding inclination. Louis et al. [15] investigated the microstructural inhomogeneity and mechanical anisotropy associated with the bedding effect for Rothbach sandstone. Chen et al. [16] studied the anisotropic properties of low Cambrian black shale at Niutitang; the effects of confining pressure and bedding angle on the black shale are also demonstrated by triaxial compression tests. Anisotropy of the rock reservoirs is also important for unconventional gas exploitation, as it is a significant parameter for production in the field. Ma et al. [17] studied the anisotropy gas permeability and its relationship with fracture structure of Longmaxi shale in the laboratory by using helium gas as permeate gas and found that the permeability parallel to the bedding of shale is about 10.4 times that perpendicular to the bedding. In addition, the anisotropy is also relative to the stress state. Feng et al. [18] revealed the anisotropic deformation and stress-dependent directional permeability of the coalbed methane reservoirs and suggested that the anisotropic properties should be considered when simulating gas flow behavior and predicting the production of coalbed methane production.

From the above studies, many experts pointed out that the anisotropy is an important factor for the unconventional gas reservoirs, and the predominant studies focused on the shale rock because shale gas production is a very hot issue in these years. As for the research on tight sandstone, another huge resource with great production potential in China, the relative research to support the field application is relatively rare. As a type of sedimentary rock, tight sandstone also has obvious anisotropy with bedding angle, and this is the prerequisite for the designing of hydrofracturing in reservoirs. So, the study on the anisotropy of tight sandstone is also necessary and significant.

In this study, the tight sandstone samples are collected from Xujiahe reservoir, which is a tight sandstone reservoir in Hubei Province. The samples are prepared with different bedding angles, and uniaxial and triaxial compression tests are carried out to investigate the anisotropy characteristics of the tight sandstone from the viewpoint of strength, mechanical parameters, and failure characters. The anisotropic index of the Xujiahe tight sandstone is also analyzed and discussed by using the transversely isotropic theory of rock mass. This study can provide effective technical support for designing and optimizing hydraulic fracturing in the tight sandstone fields.

\section{Test Profile}

2.1. Specimen Preparation. The rock core blocks for testing, the same stratum with the tight sandstone reservoirs as potential exploitation formation, are taken from Lichuan City, Hubei Province. The lithology of the rock cores is mainly dominated by gray fine sandstone. Cylinder samples are drilled with different angles with the bedding plane in the core blocks, which are, respectively, $0^{\circ}, 30^{\circ}, 45^{\circ}, 60^{\circ}$, and $90^{\circ}$, as shown in Figure 1. According to the test requirements, the samples are processed with the following properties: $50 \mathrm{~mm}$ in diameter and $100 \mathrm{~mm}$ in length, and the roughness of the two end faces of all the samples is within $0.02 \mathrm{~mm}$.

2.2. Test Equipment and Test Methods. The uniaxial and triaxial compression tests are conducted by using the mechanical equipment of MTS-815.03 in Chongqing University of China. The axial displacement control mode is used for loading all the samples, and the corresponding loading rate is $-0.001 \mathrm{~mm} / \mathrm{s}$. In the process of loading, the axial load, axial stress, axial displacement, and the circular displacement are all recorded in time, and the stress-strain curves are drawn synchronously. The used MTS equipment is shown in Figure 2.

\section{Test Results and Analysis}

3.1. Brittle Characteristics of Tight Sandstone. The mineral compositions of the tight sandstone cores are measured by using the equipment of AXS D8-Focus $X$ Bruker Ray Diffraction, and the testing results are shown in Table 1 . In this table, the quartz and feldspar are collected together as brittle minerals, and illite and chlorite are collected as clay minerals.

The brittleness of rock is evaluated based on the components of brittle minerals [19]. It is usually demonstrated that rock with a higher content of quartz and carbonate has stronger brittleness, while for rock containing more clay minerals, the brittleness will be weaker.

In this study, the calculation method for the rock brittleness index based on mineral composition is as follows [19]:

$$
I=\frac{\left(W_{Q}+W_{C}\right)}{W_{T}},
$$

where $I$ is the brittleness index of rock; $W_{Q}$ is the quartz content; $W_{C}$ is the carbonate rock content; $W_{T}$ is the total content of all minerals.

As shown in Table 1, the clay minerals in the tight sandstone are mainly illite, which has a content of $23.67 \%$. The brittle minerals in tight sandstone samples are mainly quartz and feldspar, with a total content of $76.33 \%$, consisting of $62.40 \%$ of quartz and $13.93 \%$ of carbonate. According to equation (1), it can be calculated that the brittleness index $I$ of the tight sandstone in this study equals 0.76. According to the discriminant standard of brittleness degree [19], it can be known that the brittleness of tight sandstone samples is relatively dense, so the tight sandstone studied here belongs to high brittle-fracturing tight sandstone reservoir. The greater the brittleness is, the easier it is to form a complex fracture network after hydraulic fracturing, and thus a better ideal production may be obtained during the process of gas exploitation.

3.2. Stress-Strain Curves. The results of the uniaxial and triaxial compression tests of tight sandstone samples with different dip angles and different confining pressure are shown in Table 2. 20 samples are tested in total. Under each 

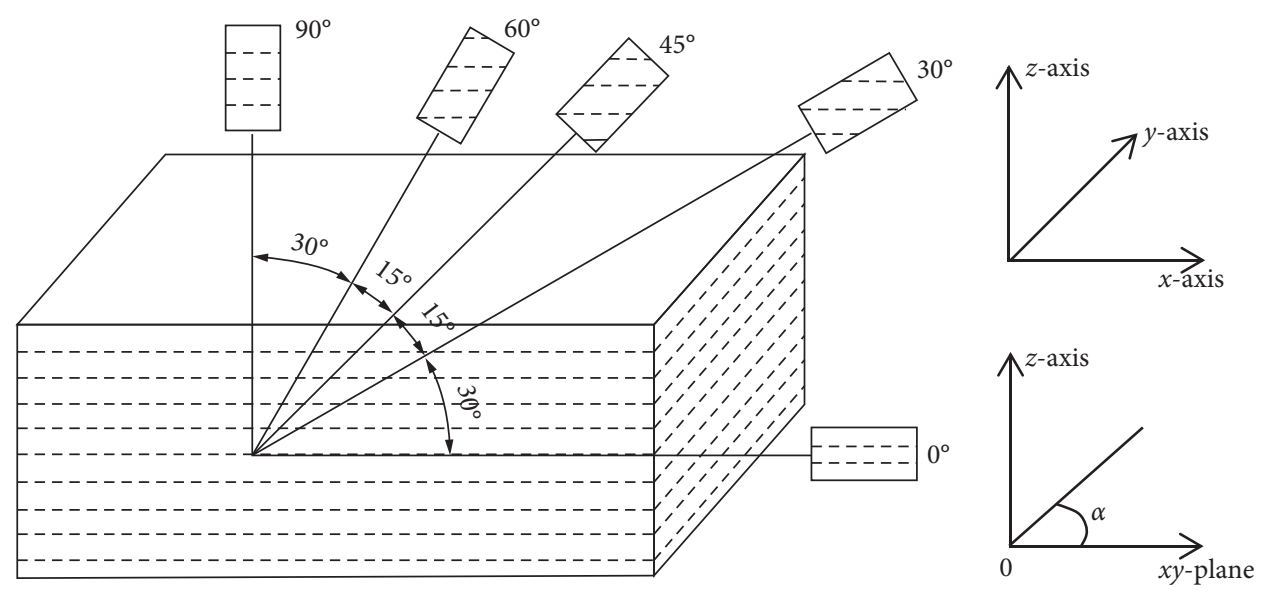

FIGURE 1: Schematic diagram of the five sampling angles with bedding plane (dip angle $a$ is the inclination angle between the bedding plane and sample drilling direction, which is $0^{\circ}, 30^{\circ}, 45^{\circ}, 60^{\circ}$, and $90^{\circ}$, respectively).

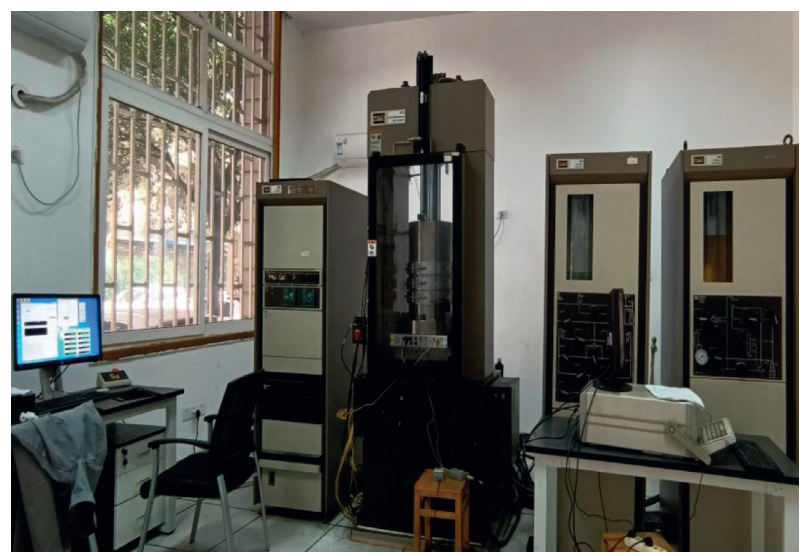

FIgURE 2: The MTS-815 system of Chongqing University.

TABLE 1: Mineral composition of tight sandstone.

\begin{tabular}{lcccc}
\hline \multirow{2}{*}{ Number of samples } & \multicolumn{2}{c}{ Brittle minerals (\%) } & \multicolumn{2}{c}{$\begin{array}{c}\text { Clay minerals } \\
\text { (\%) }\end{array}$} \\
& Quartz & Feldspar & Illite & Chlorite \\
\hline 1 & 59.85 & 14.80 & 22.00 & 3.35 \\
2 & 69.38 & 12.11 & 15.60 & 2.91 \\
3 & 57.98 & 14.88 & 23.07 & 4.08 \\
Average value & 62.40 & 13.93 & 20.22 & 3.45 \\
Gross & \multicolumn{2}{c}{76.33} & \multicolumn{2}{c}{23.67} \\
\hline
\end{tabular}

confining pressure $(0,15 \mathrm{MPa}, 30 \mathrm{MPa}$, and $45 \mathrm{MPa})$, five samples are used with dip angles of $0^{\circ}, 30^{\circ}, 45^{\circ}, 60^{\circ}$, and $90^{\circ}$, respectively. The stress-strain curves of samples with the same confining pressure and different angles are listed in Figures 3 and 4. Figure 3(a) shows the strain-stress curves of the tight sandstone samples with the same dip angle of $0^{\circ}$ under different confining pressure. Figure 3(a) shows the strain-stress curves of the tight sandstone samples with the same dip angle of $0^{\circ}$ under different confining pressure. By comparing these two pictures, the influence of dip angle can be revealed. Figure 4(a) and Figure 4(b) show the stressstrain curves of the tight sandstone samples under the same confining pressure with different dip angles. By these two pictures, the influence of dip angle can be observed more obviously.

By analyzing the data and curves in Table 2 and Figures 3 and 4, the main summaries can be made as follows:

(1) Under the same conditions, the shape and deformation characteristics of the stress-strain curves are affected by the confining pressure and bedding angle. It can be indicated from Table 2 that, for the sample with the same dip angle, with the increase in confining pressure, the peak strength and elastic modulus of tight sandstone are significantly increased. So, the confining pressure is a significant factor to influence the strength of tight sandstone.

(2) It can be seen from Figures 3 and 4 that, under the condition with the same confining pressure, obvious yield deformation appears in front of all the dip angles of the stress-strain curve. For the samples under confining pressure of $45 \mathrm{MPa}$ with a dip angle of $0^{\circ}, 30^{\circ}, 45^{\circ}$, and $60^{\circ}$, the stress-strain curve of samples immediately drops after reaching the top intensity. While this angle is $90^{\circ}$, the curves of samples present an obvious yield platform when it is close to the peak point; and, after reaching the peak point, it does not drop but shows a ductility characteristic. The reason is that when the dip angle $\alpha$ is $0^{\circ}, 30^{\circ}, 45^{\circ}$, and $60^{\circ}$, the samples present shear slip damage after reaching the peak point. While the dip angle $\alpha$ is $90^{\circ}$, the samples happen to shear expansion damage after reaching the peak point, with a chubby middle and no obvious slip lines, so the samples still have a strong bearing capacity.

\subsection{Anisotropy Characteristics Analysis}

3.3.1. Wave Velocity Anisotropy. The anisotropy in wave velocity is another important factor to reflect the anisotropic characteristics of rock mass [20]. So, in this study, we also apply this method to study the anisotropic characteristics of tight sandstone. Five groups of the samples are divided. Four 
TABLE 2: Triaxial compression testing results of samples with different strata angles.

\begin{tabular}{|c|c|c|c|c|c|c|c|}
\hline Confining pressure $(\mathrm{MPa})$ & $\begin{array}{c}\text { Dip } \\
\text { angle }\left({ }^{\circ}\right)\end{array}$ & $\begin{array}{l}\text { Peak strength } \\
(\mathrm{MPa})\end{array}$ & $\begin{array}{c}\text { Elastic modulus } \\
(\mathrm{GPa})\end{array}$ & $\begin{array}{l}\text { Poisson's } \\
\text { ratio }\end{array}$ & $\begin{array}{c}\text { Peak } \\
\text { strain (\%) }\end{array}$ & $\begin{array}{l}\text { Rupture } \\
\text { angle }\left({ }^{\circ}\right)\end{array}$ & $\begin{array}{c}\text { Residual strength } \\
(\mathrm{MPa})\end{array}$ \\
\hline \multirow{5}{*}{0} & 0 & 54.57 & 5.08 & 0.16 & 1.55 & 83 & - \\
\hline & 30 & 41.84 & 3.39 & 0.31 & 1.48 & 88 & - \\
\hline & 45 & 46.22 & 4.38 & 0.34 & 1.65 & 82 & - \\
\hline & 60 & 56.53 & 4.74 & 0.35 & 1.64 & 82.5 & - \\
\hline & 90 & 52.68 & 4.45 & 0.19 & 1.52 & 90 & - \\
\hline \multirow{5}{*}{15} & 0 & 182.15 & 9.25 & 0.15 & 2.10 & 70.5 & 90.46 \\
\hline & 30 & 158.03 & 8.42 & 0.16 & 1.91 & 69.5 & 81.98 \\
\hline & 45 & 148.07 & 8.09 & 0.21 & 2.03 & 65 & 57.98 \\
\hline & 60 & 154.30 & 7.80 & 0.21 & 2.22 & 63.5 & 59.97 \\
\hline & 90 & 154.90 & 7.52 & 0.18 & 2.15 & 68 & 57.10 \\
\hline \multirow{5}{*}{30} & 0 & 255.50 & 11.12 & 0.19 & 2.39 & 71.5 & 98.40 \\
\hline & 30 & 205.99 & 10.58 & 0.24 & 1.92 & 60 & 101.92 \\
\hline & 45 & 218.04 & 9.88 & 0.30 & 2.38 & 62.5 & 100.60 \\
\hline & 60 & 230.23 & 9.49 & 0.27 & 2.55 & 69.5 & 112.62 \\
\hline & 90 & 220.86 & 8.22 & 0.24 & 2.48 & 62 & 99.00 \\
\hline \multirow{5}{*}{45} & 0 & 333.19 & 14.24 & 0.17 & 2.59 & 61 & 142.03 \\
\hline & 30 & 272.11 & 12.63 & 0.21 & 2.06 & 56.5 & 154.15 \\
\hline & 45 & 275.82 & 11.94 & 0.26 & 2.27 & 57 & 129.82 \\
\hline & 60 & 282.80 & 11.40 & 0.23 & 2.80 & 69.5 & 137.48 \\
\hline & 90 & 277.60 & 10.81 & 0.21 & 2.96 & 63 & - \\
\hline
\end{tabular}

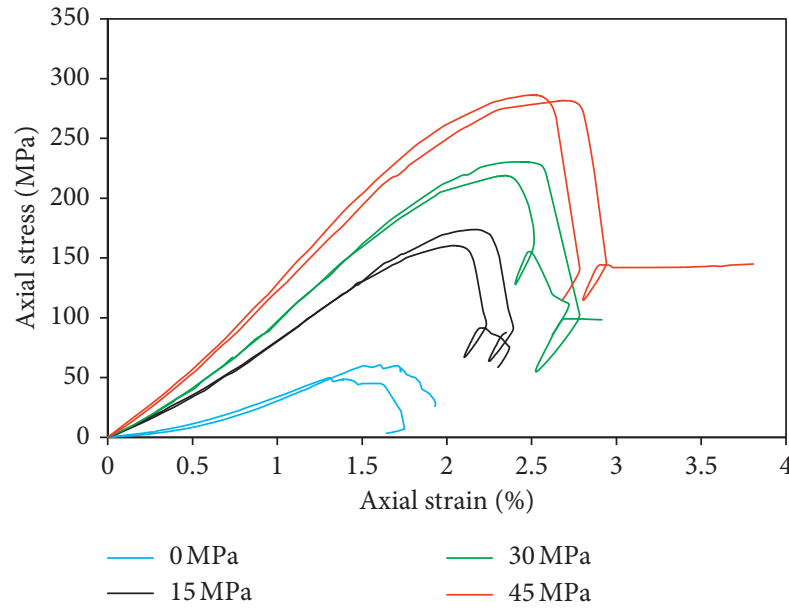

(a)

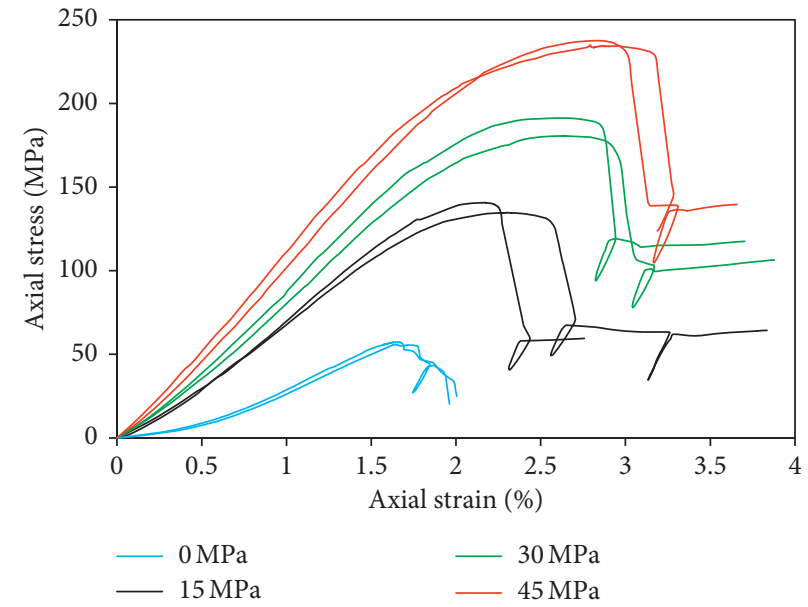

(b)

Figure 3: Typical curves of stress-strain of tight sandstone samples with the same dip angle under different confining pressure. (a) Angle $\alpha=0^{\circ}$. (b) Angle $\alpha=60^{\circ}$.

ones for dip angle are prepared for this test. So, 20 samples are used for the measurement of the longitudinal wave velocity before the mechanical tests as shown in Table 2. All the tests are conducted by using the device of Nonmetallic Ultrasonic Detector JL-IUA6(a). According to the longitudinal wave velocity test on the tight sandstone samples, the anisotropy properties of tight sandstone can be revealed in some aspects. The experimental results of ultrasonic velocity for samples are shown in Table 3. The change regularities of longitudinal wave velocity with different dip angles of all the samples are shown in Figure 5.

From Table 3, it can be seen that the longitudinal wave velocity decreases gradually with the dip angle. When the dip angle equals $0^{\circ}$, the longitudinal wave propagates parallel to the bedding surface, consuming the minimal energy and the shortest penetrating time, thus having the greatest wave velocity. But, for the samples with the dip angle of $90^{\circ}$, the propagation direction of the longitudinal wave is perpendicular to the bedding planes, so the longitudinal wave has to penetrate the bedding layers to spread, which causes the maximum energy consumption and the longest travel time and results in the minimum wave velocity in the process of spreading. So, the wave velocity is a factor to reflect the anisotropy of the tight sandstone. The ratio of the wave velocity of the direction in $0^{\circ}$ and $90^{\circ}$ is 1.206 , which is somewhat lower than that of the Longmaxi shale [11]. Therefore, the anisotropy of tight sandstone exists but is lower than that of shale. 


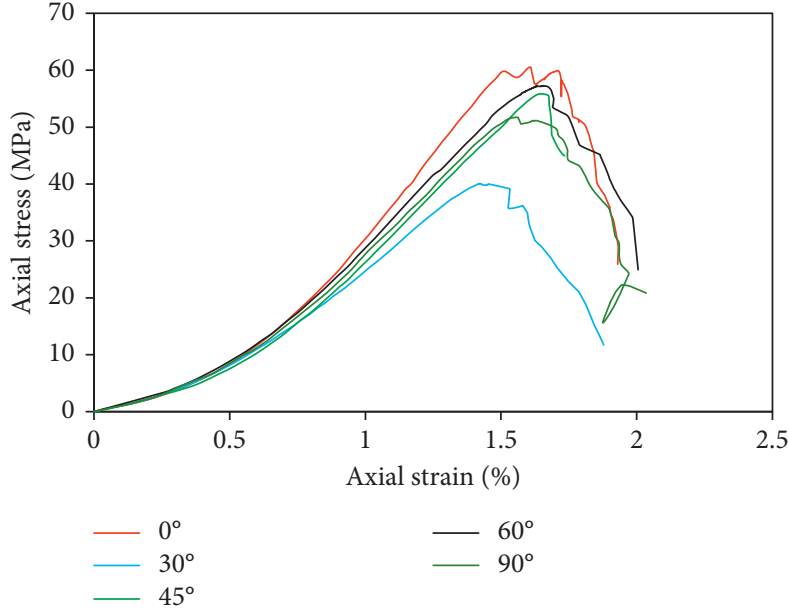

(a)

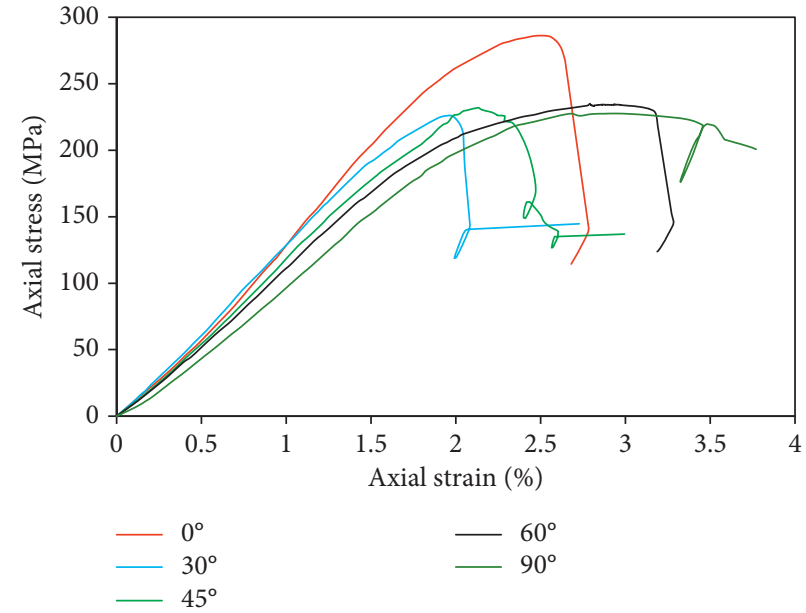

(b)

Figure 4: Typical curves of stress-strain of tight sandstone samples with different dip angle under the same confining pressure. (a) Confining pressure $\sigma_{3}=0 \mathrm{MPa}$. (b) Confining pressure $\sigma_{3}=45 \mathrm{MPa}$.

TABLE 3: Longitudinal wave velocity of tight sandstone samples with different dip angle.

\begin{tabular}{|c|c|c|c|c|c|}
\hline Dip angle $\left({ }^{\circ}\right)$ & \multicolumn{4}{|c|}{ Longitudinal wave velocity $(\mathrm{m} / \mathrm{s})$} & Average velocity $(\mathrm{m} / \mathrm{s})$ \\
\hline 0 & $\begin{array}{l}2331 \\
2254\end{array}$ & $\begin{array}{l}2331 \\
2354\end{array}$ & $\begin{array}{l}2272 \\
2311\end{array}$ & $\begin{array}{l}2259 \\
2419\end{array}$ & 2316 \\
\hline 30 & $\begin{array}{l}2156 \\
2155\end{array}$ & $\begin{array}{l}2176 \\
2111\end{array}$ & $\begin{array}{l}2028 \\
2092\end{array}$ & $\begin{array}{l}2261 \\
2270\end{array}$ & 2156 \\
\hline 45 & $\begin{array}{l}2068 \\
2022 \\
\end{array}$ & $\begin{array}{l}2088 \\
2072 \\
\end{array}$ & $\begin{array}{l}1973 \\
2065\end{array}$ & $\begin{array}{c}1919 \\
-\end{array}$ & 2030 \\
\hline 60 & $\begin{array}{l}2036 \\
2097 \\
\end{array}$ & $\begin{array}{l}2015 \\
1937 \\
\end{array}$ & $\begin{array}{l}1981 \\
1981\end{array}$ & $\begin{array}{l}1873 \\
2008\end{array}$ & 1991 \\
\hline 90 & $\begin{array}{l}1994 \\
1966\end{array}$ & $\begin{array}{l}1944 \\
1803\end{array}$ & $\begin{array}{l}1878 \\
1959\end{array}$ & $\begin{array}{c}1906 \\
-\end{array}$ & 1921 \\
\hline
\end{tabular}

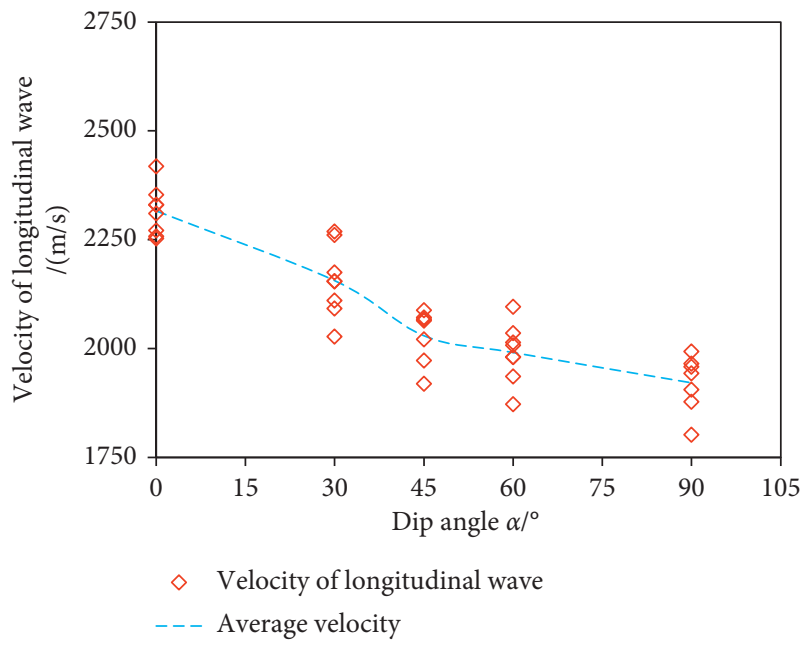

FIGURE 5: Longitudinal wave velocity of tight sandstone samples with different dip angles.

3.3.2. Elastic Modulus Anisotropy. Elastic modulus is a basic mechanical parameter, which is also an important factor to show the anisotropy of the tight sandstone. Based on the uniaxial/triaxial compression tests in the laboratory, all the elastic moduli of the 20 tested samples are calculated. The triaxial compression tests are conducted under the confining pressures of $15 \mathrm{MPa}, 30 \mathrm{MPa}$, and $45 \mathrm{MPa}$. Table 4 shows the elastic modulus anisotropy values of the tight sandstone samples under different confining pressures and dip angles. As shown in Figure 6, when the confining pressure is $0 \mathrm{MPa}$ (which corresponds to the uniaxial compression test), with the increase of dip angle, the change of the elastic modulus is approximately a $\mathrm{U}$ shape. When the dip angle is $0^{\circ}$, the elastic modulus has a maximum value of $5.08 \mathrm{GPa}$; but when the dip angle equals $30^{\circ}$, the elastic modulus has a minimum value of $3.39 \mathrm{GPa}$. In addition, when the confining pressure is, respectively, $15 \mathrm{MPa}, 30 \mathrm{MPa}$, and $45 \mathrm{MPa}$, with the increase of the dip angle, the elastic modulus decreases gradually.

For the condition with different confining pressure, the calculation method of the elastic modulus anisotropy [21] is as follows:

$$
R_{E}=\frac{E_{\max }}{E_{\min }},
$$

where $R_{E}$ is the anisotropy degree of elastic modulus, $E_{\max }$ is the maximum elastic modulus of the sample which 
TABle 4: Anisotropy degree of elastic modulus.

\begin{tabular}{lccc}
\hline Confining pressure $(\mathrm{MPa})$ & Max. elastic modulus $(\mathrm{GPa})$ & Min. elastic modulus $(\mathrm{GPa})$ & Degree of anisotropy \\
\hline 0 & 5.24 & 3.19 & 1.64 \\
15 & 9.41 & 7.50 & 1.25 \\
30 & 11.15 & 8.22 & 1.36 \\
45 & 14.47 & 10.75 & 1.35 \\
\hline
\end{tabular}

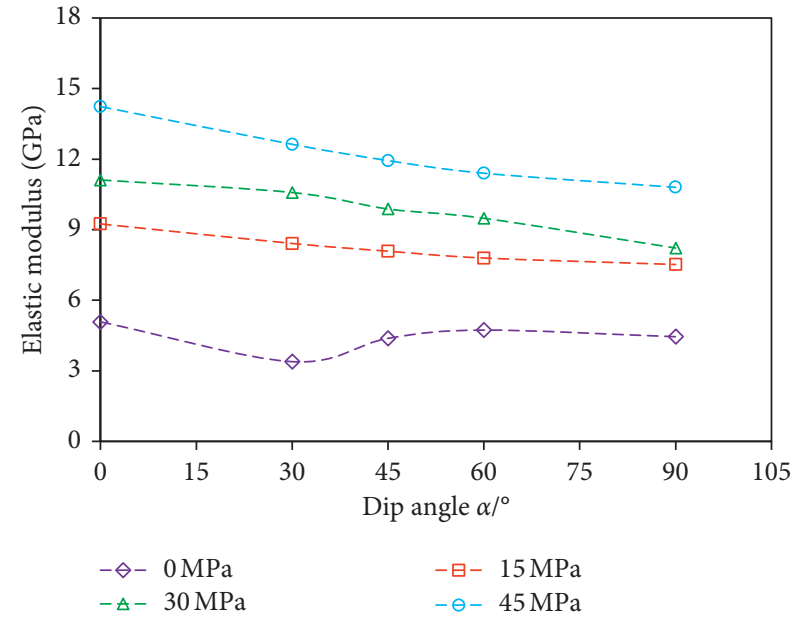

FIgURE 6: Elastic modulus anisotropy of the tight sandstone samples with different dip angles when subjected to different confining pressure.

corresponds to the dip angle of $0^{\circ}$, and $E_{\min }$ is the minimum elastic modulus.

According to equation (2), the anisotropy degree of the elastic modulus was calculated, as shown in Table 4. For the samples under the confining pressure of $0 \mathrm{MPa}$, the elastic modulus of the tight sandstone is of obvious anisotropy. The anisotropy degree of $R_{E}$ equals 1.64. For the samples under the confining pressure of $15 \mathrm{MPa}, 30 \mathrm{MPa}$, and $45 \mathrm{MPa}$, the anisotropy degree $\left(R_{E}\right)$ of the elastic modulus becomes lower than that under the confining pressure of $0 \mathrm{MPa}$, ranging between 1.25 and 1.36. Therefore, the existence of confining pressure has decreased the anisotropy of the tight sandstone of Xujiahe Formation, which causes the anisotropy of elastic modulus to become much weaker. As for the laboratory test of hydraulic fracturing of tight sandstone samples, the hydraulic fracturing calculation model, and the numerical simulation of the Xujiahe tight sandstone, considering that the anisotropy degree of elastic modulus is much weaker when subjected to three-directional stress state, the elastic modulus in an isotropic plane and vertical plane isotropic elastic modulus can be taken as the average elastic modulus for a rough estimation. But, for an accurate calculation, it is still suggested that the anisotropy influence of elastic modulus cannot be neglected.

3.3.3. Compressive Strength Anisotropy. Figure 7 shows the anisotropy curves of triaxial compressive strength for samples with different dip angles under different confining pressures. Under the same confining pressure, for the samples with the dip angles of $0^{\circ}$ and $90^{\circ}$ (the dip angle of $0^{\circ}$

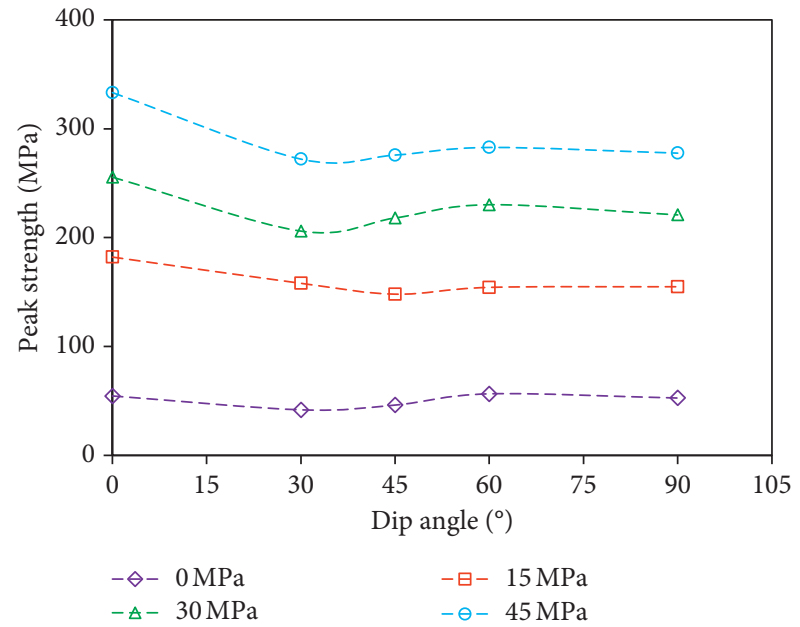

FIgURE 7: Triaxial compression strength anisotropy of samples with different strata angles.

corresponds to the maximum strength), the compressive strength of samples is relatively high. For samples with the dip angles of $30^{\circ}$ and $45^{\circ}$, the compressive strength of samples is relatively low. The overall evolution of the compression strength performs a $U$ shape, which is high at both sides and low in the middle location. Under the condition of different confining pressures, the calculation method for the anisotropy degree of the compressive strength anisotropy of $R_{P}[21]$ is as follows:

$$
R_{P}=\frac{\sigma_{\max }}{\sigma_{\min }},
$$

where $R_{P}$ is the anisotropy degree of compressive strength, $\sigma$ (max) is the maximum compressive strength of samples, which corresponds to the dip angle of $0^{\circ}$, and $\sigma_{\min }$ is the minimum compressive strength.

According to equation (3), the anisotropy degree of the compressive strength of the tight sandstone samples in this study can be calculated, as shown in Table 5. With an increase in the confining pressure, the anisotropy degree of the compressive strength decreases. When the confining pressure is $0 \mathrm{MPa}$, the anisotropy degree of the compressive strength, $R_{P}$, is 1.51 ; when the confining pressure is $15 \mathrm{MPa}, 30 \mathrm{MPa}$, and $45 \mathrm{MPa}$, the anisotropy degree of the compressive strength, $R_{P}$, ranges from 1.24 to 1.30 . Therefore, from the viewpoint of compressive strength, it has an obvious anisotropy. The confining pressure has a negligible influence on the anisotropy degree for the tight sandstone in this study. In the field reservoir of the tight sandstone of Xujiahe Formation, the influences of the anisotropy and the in situ stress state should both be considered for gas production. 
TABLE 5: Triaxial compression strength anisotropy of tight sandstone samples.

\begin{tabular}{lccc}
\hline Confining pressure $(\mathrm{MPa})$ & Max. strength $(\mathrm{MPa})$ & Min. strength $(\mathrm{MPa})$ & Anisotropy degree of compressive strength \\
\hline 0 & 60.57 & 40.05 & 1.51 \\
15 & 188.92 & 145.09 & 1.30 \\
30 & 260.44 & 201.24 & 1.29 \\
45 & 335.03 & 271.16 & 1.24 \\
\hline
\end{tabular}

3.3.4. Anisotropy of Fracture Morphology. Figure 8 shows failure mode under the conditions of different confining pressure and different dip angles. The failure modes of the samples can be mainly divided into three types: splitting failure, shear failure, and shear-expansion failure.

When the confining pressure is $0 \mathrm{MPa}$, the predominant failure mode of all the samples is splitting failure, but some differences exist among the samples with different dip angles. For instance, the sample with the dip angle of $0^{\circ}$ has a main splitting fracture and several secondary fractures, and some secondary fractures are inclined, showing shear failure performance. This is a reflection that the matrix perpendicular to the bedding direction has the greatest strength. As for the sample with the dip angle of $90^{\circ}$, only one splitting fracture appears on the sample surface, parallel to the axial loading direction. This indicates that the matrix along the bedding direction has a low strength. For the samples with the dip angles of $30^{\circ}, 45^{\circ}$, and $60^{\circ}$, the failure fracture is straight in the middle location and somewhat inclined at each end. This shows that the propagation direction of the failure fracture may be influenced by the bedding plane. So, under the uniaxial compression test (confining pressure $=0 \mathrm{MPa}$ ), anisotropy exists in the review point of failure morphology.

Under triaxial compression testing condition $(15 \mathrm{MPa}$ and $30 \mathrm{MPa}$ ), the difference in failure morphology remains existent for the samples with different dip angles. For example, the sample with $0^{\circ}$ dip angle has a steep failure surface, but the failure surface of the sample with dip angle of $90^{\circ}$ is much gentler. When the dip angle ranges from $30^{\circ}$ to $60^{\circ}$, the failure surface has an inclination angle between the cases of $0^{\circ}$ and $90^{\circ}$, but the failure surface is already not a plane surface but a curved one. That is to say, due to the existence of bedding angle, it has caused the failure surface to be a curved surface. With respect to the condition of high confining pressure $(45 \mathrm{MPa})$, the failure mode has become shear-dilatant state. There is one main failure surface, but the aperture of this surface is very small, and there are numerous small fissures around this surface. The middle location of the sample has expanded, showing a drum shape. Moreover, except the cases with dip angles of $0^{\circ}$ and $90^{\circ}$, the failure surfaces of the samples are all curved surfaces under the confining pressure of $45 \mathrm{MPa}$.

From the above study, one can deduce that the existence of confining pressure has largely changed the failure modes for the tight sandstone. During the increase process of the confining pressure $(0 \mathrm{MPa} \longrightarrow 15 \mathrm{MPa} \longrightarrow 30 \mathrm{MPa} \longrightarrow 45 \mathrm{MPa})$, the failure morphology also changes from splitting failure to shear failure and to dilatant failure. Combining with the stressstrain curves, the greater the confining pressure is, the larger strength and larger deformation both appear. So, in the process for gas production in such tight sandstone reservoir, the influence of confining pressure cannot be ignored. The tight sandstone reservoir usually has a large burying depth; the in situ stress state of the rock is under three-directional stress state. When considering the hydrofracturing for the reservoir, the influence of stress state on the strength and fracturing modes of the tight sandstone should also be thoroughly considered.

On the other hand, under the triaxial compression condition, the application of confining pressure has decreased the anisotropy degree from viewpoints of the strength and mechanical parameters, but the anisotropy performances of the failure morphology still cannot be neglected. For instance, the inclination angle between the axial loading direction and the failure surface is different when the samples have different dip angle and so is the morphology of the failure surface. The sample with a dip angle of $0^{\circ}$ has a plane failure surface, and there are curved surfaces for the samples with dip angles of $30^{\circ}$ and $45^{\circ}$; and numerous small fissures also appear around the failure surface for the samples with dip angles of $60^{\circ}$ and $90^{\circ}$. That is to say, even so the confining pressure is high, due to the anisotropy of the tight sandstone, the difference in failure morphology remains existent. How will such a character influence the cracknet propagation of the tight sandstone under hydrofracture remains unknown, so further investigation is still needed.

\section{Application}

4.1. Material Parameters of Approximate Isotropic Material Models. From the above study, we can find that the tight sandstone of Xujiahe Formation has a certain degree of anisotropy, but the anisotropy will be low when subjected to confining pressure. In addition, by observing the sample morphology and analyzing the mechanical testing results, the tight sandstone in this study can be regarded as a type of transversely isotropic material, and the stress-strain relationship (flexibility matrix) of this material can be expressed as [21, 22]

$$
\left[\begin{array}{c}
\varepsilon_{x} \\
\varepsilon_{y} \\
\varepsilon_{z} \\
\gamma_{x y} \\
\gamma_{y z} \\
\gamma_{z x}
\end{array}\right]=\left[\begin{array}{cccccc}
\frac{1}{E} & -\frac{v}{E} & -\frac{v^{\prime}}{E} & 0 & 0 & 0 \\
-\frac{v}{E} & \frac{1}{E} & -\frac{v^{\prime}}{E} & 0 & 0 & 0 \\
--\frac{v^{\prime}}{E} & -\frac{v^{\prime}}{E} & \frac{1}{E^{\prime}} & 0 & 0 & 0 \\
0 & 0 & 0 & \frac{1}{G} & 0 & 0 \\
0 & 0 & 0 & 0 & \frac{1}{G^{\prime}} & 0 \\
0 & 0 & 0 & 0 & 0 & \frac{1}{G^{\prime}}
\end{array}\right]\left[\begin{array}{c}
\sigma_{x} \\
\sigma_{y} \\
\sigma_{z} \\
\sigma_{x y} \\
\sigma_{y z} \\
\sigma_{z x}
\end{array}\right],
$$




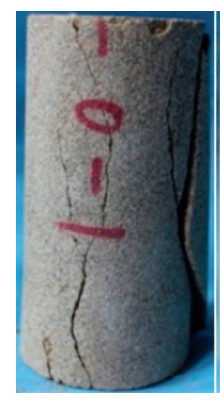

$0 \mathrm{MPa}$

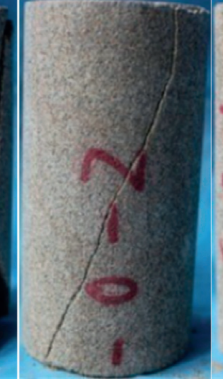

$15 \mathrm{MPa}$

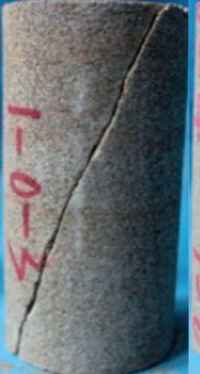

$30 \mathrm{MPa}$

(a)

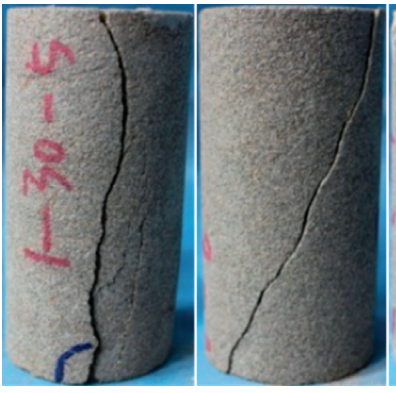

$0 \mathrm{MPa}$
$15 \mathrm{MPa}$

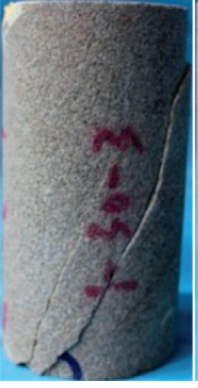

$30 \mathrm{MPa}$

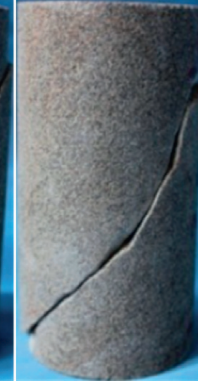

$45 \mathrm{MPa}$

(b)

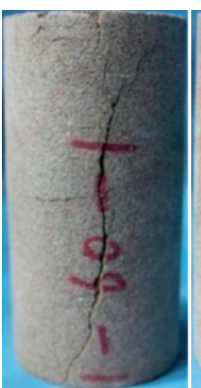

$0 \mathrm{MPa}$

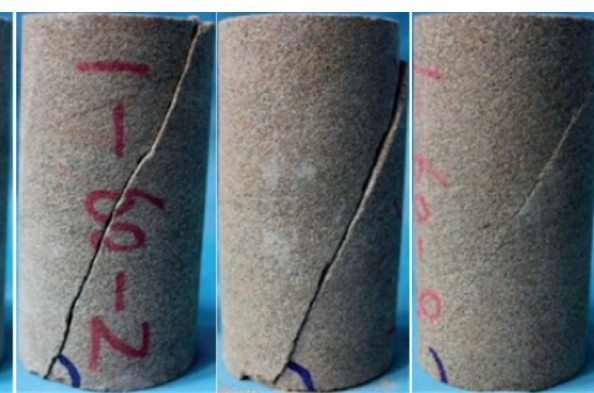

$15 \mathrm{MPa}$

$30 \mathrm{MPa}$

$45 \mathrm{MPa}$

(c)

(d)

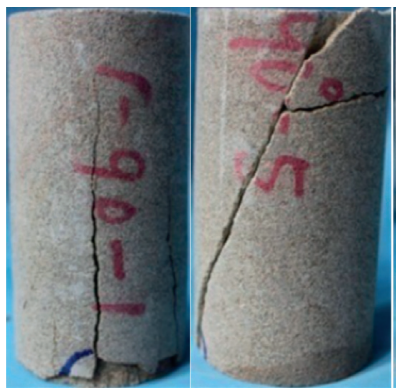

$0 \mathrm{MPa}$

$15 \mathrm{MPa}$

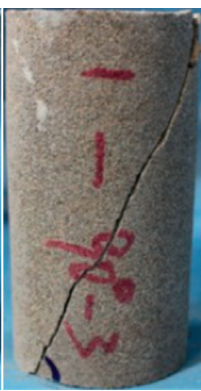

$30 \mathrm{MPa}$

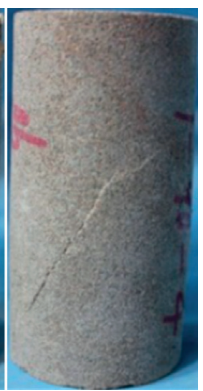

$45 \mathrm{MPa}$

(e)

Figure 8: Fracture morphology of tight sandstone samples under different confining pressure. (a) Dip angle $\alpha=0^{\circ}$. (b) Dip angle $\alpha=30^{\circ}$. (c) Dip angle $\alpha=45^{\circ}$. (d) Dip angle $\alpha=60^{\circ}$. (e) Dip angle $\alpha=90^{\circ}$.

where $E$ and $E^{\prime}$ are elastic moduli of the isotropic plane and the plane perpendicular to the isotropic plane, respectively; $G$ and $G^{\prime}$ are shear moduli of the isotropic plane and the plane perpendicular to the isotropic plane, respectively; $v$ and $v^{\prime}$ both are Poisson's ratio, and they represent lateral strain reduction of each isotropic plane which is caused by tensile stress in the same plane and lateral strain reduction of each isotropic plane that is caused by tensile stress which is perpendicular to this plane.

From the above study, we find that the elastic modulus changes with the dip angle. That is, when the axial direction of the sample has a different dip angle, its elastic modulus also changes. In reality, we concern not only the elastic modulus of the isotropic plane and its perpendicular plane but also want to know the modulus of the plane that has an inclination angle with the isotropic plane.
The modulus of one plane which has an inclination angle of $\alpha$ can be expressed as [23]

$$
\frac{1}{E_{\alpha}}=\frac{4}{\sin \alpha}+\left(\frac{1}{G^{\prime}}-\frac{2 \nu}{E}\right) \stackrel{2}{\cos \alpha \sin \alpha} \alpha+\frac{\cos \alpha}{E^{\prime}},
$$

where $E$ is the elastic modulus of the isotropic plane (corresponding to the sample with a dip angle of $90^{\circ}$ ) and $E^{\prime}$ and $G^{\prime}$ are the elastic modulus and shear modulus of the plane perpendicular to the isotropic plane (corresponding to the sample with a dip angle of $0^{\circ}$ ).

By a transformation for equation (5), one obtains

$$
\frac{1}{E_{\alpha}}=\left(\frac{1+2 v}{E}-\frac{2}{G^{\prime}}+\frac{1}{E^{\prime}}\right) \sin ^{4} \alpha+\left(\frac{1}{G^{\prime}}-\frac{2 v}{E}-\frac{2}{E^{\prime}}\right) \sin ^{2} \alpha+\frac{1}{E^{\prime}} \text {. }
$$


In this study, the mechanical parameters of the isotropic plane and its perpendicular plane are obtained for conducting uniaxial and triaxial compression tests. Based on equation (6), the relationship between the reciprocal of elastic modulus of plane with any angle to the isotropic plane $(1 / E \alpha)$ and $\stackrel{2}{\sin } \alpha$ can be drawn. Figure 9 gives the relationship of $1 / E_{\alpha}$ and $\sin \alpha$ of Xujiahe tight sandstone in this study when subjected to different confining pressures. Fitting curves are also drawn in Figure 9.

According to the fitting curves in Figure 9 and equation (6), the five independent material parameters of tight sandstone can be calculated under different confining pressure. The calculating results are shown in Table 6.

From the above study, we can find that the difference between the elastic moduli of the isotropic plane and its perpendicular plane is within $14.2 \%-32.9 \%$. The difference between Poisson's ratios of the isotropic plane and its perpendicular plane is about $16.6 \%-21.3 \%$. The difference between the shear moduli ranges between $6.9 \%$ and $22.9 \%$. Such anisotropy degrees of the tight sandstone are not obvious enough when compared to other rock masses, such as shale [23]. So, for some rough and simplified estimation, we also regarded the tight sandstone as a type of isotropic material. Then the independent mechanical parameters can be reduced to three equivalent ones. A suggested method for the calculation of the equivalent three mechanical parameters is as follows:

$$
\begin{aligned}
& E_{s}=\frac{\left(E+E^{\prime}\right)}{2}, \\
& v_{s}=\frac{\left(\nu+\nu^{\prime}\right)}{2}, \\
& G_{s}=\frac{\left(G+G^{\prime}\right)}{2} .
\end{aligned}
$$

where $E_{s}, V_{s}$, and $G_{s}$ are the three estimated equivalent mechanical parameters.

If we want to simplify the Xujiahe tight sandstone into an isotropic rock mass (just for some rough estimations), the three estimated equivalent mechanical parameters can be calculated by using equation (7). The calculated results are shown in Table 7.

4.2. The Values of $c$ and $\varphi$. From the Coulomb-Navier criterion [22], when a rock undergoes shear fracture along a plane, it is related to not only the shear stress but also the normal stress loaded on this plane. The fracture usually develops along the most unfavorable plane on which the shear stress has a maximum value. On this plane, when the shear stress exceeds the shear strength envelope, shear failure occurs. This criterion is expressed as [22]

$$
\left.\begin{array}{l}
|\tau|=c+f \sigma \\
\tau=\frac{\sigma_{1}-\sigma_{3}}{2} \sin 2 \theta \\
\sigma=\frac{\sigma_{1}+\sigma_{3}}{2}+\frac{\sigma_{1}-\sigma_{3}}{2} \cos 2 \theta
\end{array}\right\}
$$

where $\tau$ and $\sigma$ are the shear stress and normal stress of shear fracture surface; $c$ is the inherent cohesion strength of rocks; $f$ is internal friction coefficient of rocks; $\theta$ is the angle between the normal direction of the shear plane and maximum principal stress.

After simplifying equations (8) and (9), we can obtain

$$
c=\frac{\sigma_{1}-\sigma_{3}}{2}(\sin 2 \theta-f \cos 2 \theta)-\frac{f\left(\sigma_{1}+\sigma_{3}\right)}{2} .
$$

To find a differential value of $c$ for equation (9), one can obtain the maximum shear stress and can obtain

$$
\tan 2 \theta=\frac{-1}{f}
$$

From equation (10), it can be seen that $90^{\circ}<2 \theta<180^{\circ}$ and that

$$
\left.\begin{array}{l}
\sin 2 \theta=\left(1+f^{2}\right)^{-1 / 2} \\
\cos 2 \theta=-f\left(1+f^{2}\right)^{-1 / 2}
\end{array}\right\} .
$$

The Coulomb-Navier criterion can be obtained by substituting equation (11) into equation (9):

$$
2 c=\sigma_{1}\left[\left(1+f^{2}\right)^{1 / 2}-f\right]-\sigma_{3}\left[\left(1+f^{2}\right)^{1 / 2}+f\right] .
$$

The relationship between the axial stress $\sigma_{1}$ and the confining pressure $\sigma_{3}$ is plotted, and the cohesion strength $c$ and internal friction angle $\varphi$ of the Coulomb-Navier criterion are calculated according to the following equation:

$$
\left.\begin{array}{l}
c=b \frac{1-\sin \phi}{2 \cos \phi} \\
\kappa=\sin ^{-1} \frac{m-1}{m+1}
\end{array}\right\},
$$

where $m$ and $b$ are the slope and intercept of the relationship curve of axial stress $\sigma_{1}$ and confining pressure $\sigma_{3}$. The relationship curves of axial stress $\sigma_{1}$ and confining pressure $\sigma_{3}$ of different samples with different dip angles are shown in Figure 10. By fitting the curve linearly, the slope $m$ and the intercept $b$ of the fitted straight line can be obtained, and the cohesion $c$ and internal friction angle $\varphi$ of the Coulomb-Navier criterion can also be calculated by substituting the values of $m$ and $b$ into equation (13). The detailed results are shown in Table 8.

Because cohesion strength $c$ and internal friction angle $\varphi$ of the samples with different dip angles change a little, in the numerical simulation of hydraulic fracturing model of the tight sandstone reservoir of the Xujiahe Formation, we suggest that the cohesion strength and internal friction angle can be replaced by the average values of cohesion strength and internal friction angle.

4.3. Stimulating Pressure. Referring to the horizontal well of the Jianghan oilfield reservoir [24], an indoor three-axis hydraulic fracturing physical simulation system was applied 


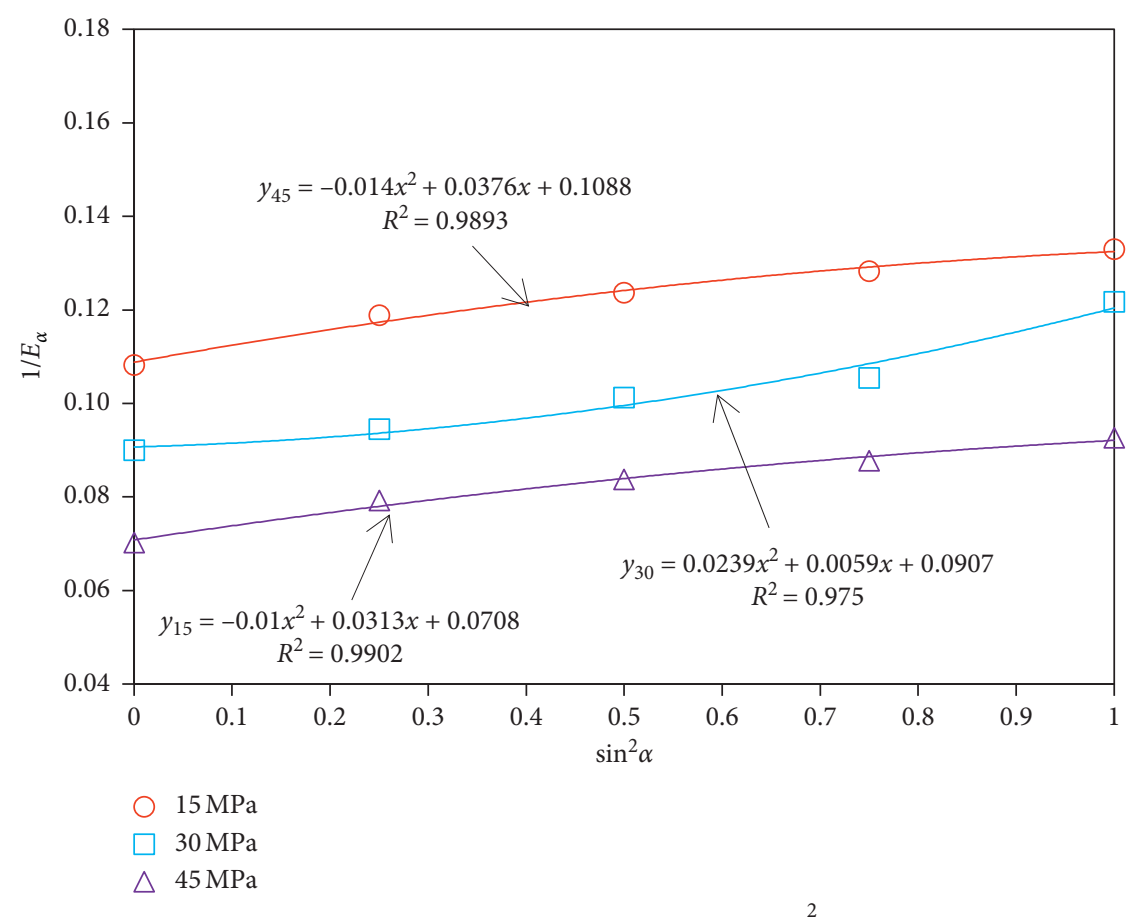

FIGURE 9: Fitting curves of the reciprocal of elastic modulus $\left(1 / E_{\alpha}\right)$ versus $\sin ^{2} \alpha$ under different confining pressures.

TABLE 6: The five independent parameters of the tight sandstone samples.

\begin{tabular}{lccccc}
\hline Confining pressure $(\mathrm{MPa})$ & $E(\mathrm{GPa})$ & $E^{\prime}(\mathrm{GPa})$ & $v$ & $v^{\prime}$ & $G^{\prime}(\mathrm{GPa})$ \\
\hline 0 & 5.08 & 4.45 & 0.16 & 0.19 & 1.74 \\
15 & 9.191 & 7.553 & 0.15 & 0.182 & 3.296 \\
30 & 11.025 & 8.299 & 0.19 & 0.236 & 4.095 \\
45 & 14.124 & 10.858 & 0.17 & 0.214 & 4.710 \\
\hline
\end{tabular}

Note: $G$ is an independent parameter that can be calculated using $G=E / 2(1+v)$.

TABLE 7: The three independent parameters of the tight sandstone samples.

\begin{tabular}{lccc}
\hline Confining pressure $(\mathrm{MPa})$ & $E_{s}(\mathrm{GPa})$ & $v_{s}$ & $G_{s}(\mathrm{GPa})$ \\
\hline 0 & 4.765 & 0.175 & 1.805 \\
15 & 8.372 & 0.166 & 3.246 \\
30 & 9.662 & 0.213 & 3.726 \\
45 & 12.491 & 0.192 & 4.591 \\
\hline
\end{tabular}

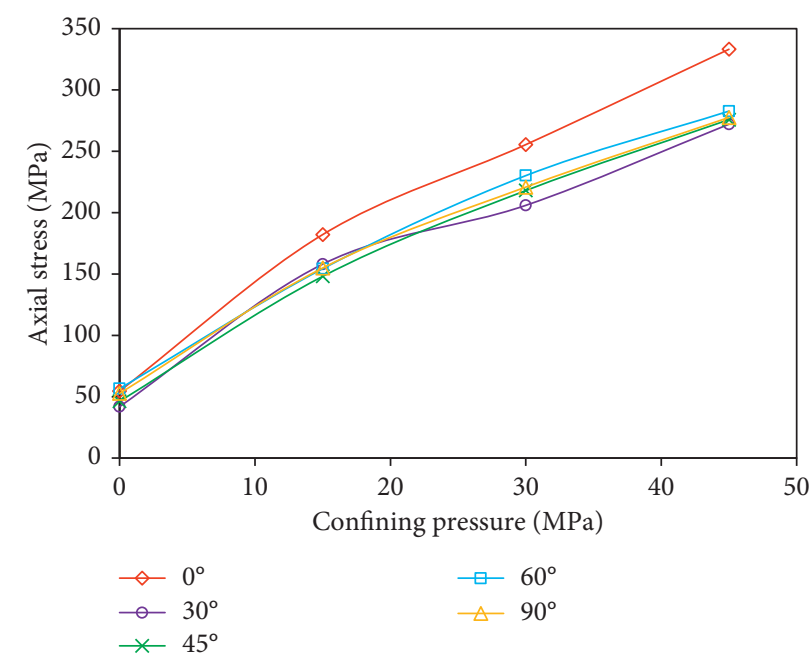

FIGURE 10: Relationship of confining pressure and axial stress of tight sandstone with different dip angle. 
TABle 8: Parameters of Coulomb-Navier criterion of tight sandstone with different dip angles.

\begin{tabular}{lcccccc}
\hline$\alpha\left(^{\circ}\right)$ & $m$ & $B(\mathrm{MPa})$ & $\varphi\left(^{\circ}\right)$ & $c(\mathrm{MPa})$ & Theory $q\left(^{\circ}\right)$ & 67.9 \\
\hline 0 & 6.06 & 69.97 & 45.8 & 14.21 & 65.8 & 67.7 \\
30 & 4.93 & 58.68 & 41.5 & 13.21 & 62.0 \\
45 & 5.06 & 58.21 & 42.1 & 12.94 & 66.0 & 61.5 \\
60 & 5.03 & 67.75 & 42.0 & 15.10 & 66.0 & 67.5 \\
90 & 4.94 & 65.40 & 41.6 & 14.71 & 64.8 & 66.3 \\
Average & 5.20 & 64.00 & 42.6 & 14.04 & 64.6 \\
\hline
\end{tabular}

TABle 9: Model parameters.

\begin{tabular}{lcccccc}
\hline $\begin{array}{l}\sigma_{H} \\
(\mathrm{MPa})\end{array}$ & $\begin{array}{c}\sigma_{V} \\
(\mathrm{MPa})\end{array}$ & $\begin{array}{c}\sigma_{h} \\
(\mathrm{MPa})\end{array}$ & $\begin{array}{c}\sigma_{t} \\
(\mathrm{MPa})\end{array}$ & $\begin{array}{c}E_{S} \\
(\mathrm{GPa})\end{array}$ & $\begin{array}{c}v_{S} \\
(\mathrm{MPa})\end{array}$ & $\begin{array}{c}G_{S} \\
(\mathrm{GPa})\end{array}$ \\
\hline 13.12 & 13.03 & 11.15 & 2.51 & 8.37 & 0.17 & 3.27 \\
\hline
\end{tabular}

to simulate the fracturing process in the open-hole stage. The model parameters for this reservoir are shown in Table 9.

According to the model parameters in Table 9, equation (14) can be used to calculate the bursting pressure $P$ [24]:

$$
P=\frac{3 \sigma_{h}-\sigma_{H}-\sigma_{t}-\left[\beta\left(1-2 v_{s}\right) /\left(1-v_{s}\right)-\varphi\right] p_{p}}{1-\left[\beta\left(1-2 v_{s}\right) /\left(1-v_{s}\right)-\varphi\right]},
$$

where $\sigma_{H}$ is the maximum horizontal in situ stress; $\sigma_{V}$ is the vertical in situ stress; $\sigma_{h}$ is the minimum horizontal in situ stress; $\sigma_{t}$ is the tensile strength; $v_{s}$ is Poisson's ratio of reservoir; $\beta$ is the effective stress coefficient; $\phi$ is the porosity degree of the reservoir; $P_{P}$ is the pore pressure of the reservoir.

Regardless of the filtration effect with putting the in situ stresses and other parameters into equation (14), it is calculated that the value of fracture pressure is $22.67 \mathrm{MPa}$. The bursting pressure is $22.02 \mathrm{MPa}$ from the result of the hydraulic fracturing test. The field-testing value has only a difference of $0.65 \mathrm{MPa}$ from the theoretical value in this study. So, we think it is still reasonable to treat the Xujiahe tight sandstone reservoir as an isotropic rock formation. However, if the tight sandstone has higher anisotropy performance, we should still regard it as anisotropy material to avoid deviation.

\section{Conclusions}

In this study, a series of uniaxial and triaxial compression tests have been conducted for tight sandstone of Xujiahe Formation with different dip angles to the bedding plane. The influences of the dip angle and confining pressure are thoroughly investigated. The main conclusions and suggestions are proposed as follows:

(1) Based on the evaluation criteria of the rock brittleness index by using mineral composition, the brittle index I of Xujiahe tight sandstone is 0.76 . So, the tight sandstone in this study is much brittle, which is a high-fracturing reservoir.

(2) The ultrasonic wave velocity of the longitudinal wave demonstrates the anisotropy characteristics of the tight sandstone; that is, the wave velocity has a maximum value when perpendicularly penetrating the bedding plane, and it decreases with an increase in the dip angle $\alpha$.

(3) Under the same confining pressure conditions, with the increasing of the dip angle $\alpha$, the elastic modulus decreases and the anisotropy degree $\left(R_{E}\right)$ of elastic modulus locates in the range of 1.25-1.36, showing an obvious but not strong anisotropy character.

(4) Under the same confining pressure, the compressive strength shows a " $U$ " shape evolution pattern, which is higher on each side and lower in the middle region, and the degree of anisotropy, $R_{P}$, is ranging from 1.24 to 1.30 , also showing a low anisotropy.

(5) The failure modes of the tight sandstone are mainly splitting fracture for the uniaxial compression test but differ in the fracture morphology; meanwhile, for the triaxial compression test, the failure mode of the tight sandstone is mainly of shear failure and sheardilatancy damage. At the same declining angle conditions, with the increase in confining pressure, the angle between principal stress and shear plane gradually decreases. The failure fracture is also different when the sample has different dip angles.

(6) The Xujiahe tight sandstone has low anisotropy from the viewpoint of mechanical parameters; thus, it can be also regarded as an isotropic material. The method to calculate the equivalent mechanical parameters is proposed. The bursting pressure of the tight sandstone formation is calculated, and it differs a little with the field data. Thus, it conforms the feasibility of regarding the low anisotropy rock formation as an isotropic one.

\section{Data Availability}

The data used to support the findings of this study are available within the article.

\section{Conflicts of Interest}

The authors declare that they have no conflicts of interest.

\section{Acknowledgments}

The research was supported by the China Scholarship Council project, the National Natural Science Foundation of China (Grant nos. 52074046, 41674022, 51834003, U1704243, and 51709113), Guizhou Provincial Geological Exploration Fund (Grant no. 208-9912-JBN-UTS0), the National Science and Technology Major Project of China 
(Grant nos. 2016ZX05060-004 and 2017ZX05036-003), Guangdong Science and Technology Department (Grant no. 2015B020238014), and Guangzhou Science Technology and Innovation Commission (Grant no. 201604016021).

\section{References}

[1] C. Zou, R. Zhu, K. Liu et al., "Tight gas sandstone reservoirs in China: characteristics and recognition criteria," Journal of Petroleum Science and Engineering, vol. 88-89, pp. 82-91, 2012.

[2] X. Ma, A. Jia, J. Tan, and D. He, "Tight sand gas development technology and practices in China," Petroleum Exploration and Development, vol. 39, no. 5, pp. 611-618, 2012.

[3] X. Yin and Q. Liu, "Anisotropic rock physics modeling of tight sandstone and applications," Journal of China University of Petroleum, vol. 40, no. 2, pp. 52-58, 2016.

[4] L.-T. Song, Z.-H. Liu, C.-C. Zhou et al., "Analysis of elastic anisotropy of tight sandstone and the influential factors," Applied Geophysics, vol. 14, no. 1, pp. 10-20, 2017.

[5] X. Li, X. Lei, and Q. Li, "Influence of bedding structure on stress-induced elastic wave anisotropy in tight sandstones," Journal of Rock Mechanics and Geotechnical Engineering, vol. 13, no. 1, pp. 1-18, 2020.

[6] F. Bashtani, B. Maini, and A. Kantzas, "Single-phase and twophase flow properties of mesaverde tight sandstone formation; random-network modeling approach," Advances in Water Resources, vol. 94, pp. 174-184, 2016.

[7] G. Liu, M. Sun, Z. Zhao, X. Wang, and S. Wu, "Characteristics and accumulation mechanism of tight sandstone gas reservoirs in the upper paleozoic, northern ordos basin, China," Petroleum Science, vol. 10, no. 4, pp. 442-449, 2013.

[8] D. Xiao, S. Lu, J. Yang, L. Zhang, and B. Li, "Classifying multiscale pores and investigating their relationship with porosity and permeability in tight sandstone gas reservoirs," Energy \& Fuels, vol. 31, no. 9, pp. 9188-9200, 2017.

[9] X.-R. Huang, J.-P. Huang, Z.-C. Li, Q.-Y. Yang, Q.-X. Sun, and W. Cui, "Brittleness index and seismic rock physics model for anisotropic tight-oil sandstone reservoirs," Applied Geophysics, vol. 12, no. 1, pp. 11-22, 2015.

[10] S. Heng, X. Liu, X. Li, X. Zhang, and C. Yang, "Experimental and numerical study on the non-planar propagation of hydraulic fractures in shale," Journal of Petroleum Science and Engineering, vol. 179, pp. 410-426, 2019.

[11] S. Heng, Y. Guo, C. Yang, J. J. K. Daemen, and Z. Li, "Experimental and theoretical study of the anisotropic properties of shale," International Journal of Rock Mechanics and Mining Sciences, vol. 74, pp. 58-68, 2015.

[12] G. Zhang, L. Wang, Y. Wu, Y. Li, and S. Yu, "Failure mechanism of bedded salt formations surrounding salt caverns for underground gas storage," Bulletin of Engineering Geology and the Environment, vol. 76, no. 4, pp. 1609-1625, 2017.

[13] W. Liu, Z. Zhang, J. Chen et al., "Physical simulation of construction and control of two butted-well horizontal cavern energy storage using large molded rock salt specimens," Energy, vol. 185, pp. 682-694, 2019.

[14] W. Liu, D. Jiang, J. Chen, J. J. K. Daemen, K. Tang, and F. Wu, "Comprehensive feasibility study of two-well-horizontal caverns for natural gas storage in thinly-bedded salt rocks in China," Energy, vol. 143, pp. 1006-1019, 2018.

[15] L. Louis, P. Baud, and T.-f. Wong, "Microstructural inhomogeneity and mechanical anisotropy associated with bedding in Rothbach sandstone," Pure and Applied Geophysics, vol. 166, no. 5-7, pp. 1063-1087, 2009.

[16] T. Y. Chen, X. T. Feng, X. W. Zhang, W. D. Cao, and C. J. Fu, "Experimental study on mechanical and anisotropic properties of black shale," Chinese Journal of Rock Mechanics and Engineering, vol. 33, no. 9, pp. 1772-1779, 2014.

[17] Y. Ma, Z. Pan, N. Zhong et al., "Experimental study of anisotropic gas permeability and its relationship with fracture structure of Longmaxi shales, Sichuan Basin, China," Fuel, vol. 180, pp. 106-115, 2016.

[18] R. Feng, S. Chen, and S. Bryant, "Investigation of anisotropic deformation and stress-dependent directional permeability of coalbed methane reservoirs," Rock Mechanics and Rock Engineering, vol. 53, no. 2, pp. 625-639, 2020.

[19] ISRM, "Suggested methods for determining tensile strength of rock materials," International Journal of Rock Mechanics and Mining Sciences, vol. 15, no. 3, pp. 99-103, 1978.

[20] Y. Wang and C. H. Li, "Investigation of the P- and S-wave velocity anisotropy of a Longmaxi formation shale by realtime ultrasonic and mechanical experiments under uniaxial deformation," Journal of Petroleum Science and Engineering, vol. 158, pp. 253-267, 2017.

[21] J. Singh, T. Ramamurthy, and R. G. Venkatappa, "Strength anisotropies in rocks," Indian Geotechnical Journal, vol. 19, no. 2, pp. 147-166, 1989.

[22] M. F. Cai, M. C. He, and D. Y. Liu, Rock Mechanics and Engineering, Science Press, Beijing, China, 2009.

[23] S. Heng, C. H. Yang, B. P. Zhang, Y. T. Guo, L. Wang, and Y. L. Wei, "Experimental research on anisotropic properties of shale," Rock and Soil Mechanics, vol. 36, no. 3, pp. 609-616, 2015.

[24] Y. L. Wei, "Ph.D. Study on the laws of hydro-fractured cracks propagation of tight sandstone gas reservoirs in Jiannan Area," Ph.D thesis, Chongqing University, Chongqing, China, 2016. 